\title{
Influence of anesthesia on hemodynamic assessment of mitral stenosis severity
}

\author{
Rafael Kuperstein ${ }^{1,2 *}$, Shir Raibman-Spector ${ }^{3 *}$, Michal Canetti $^{2}$, \\ Yishay Wasserstrum ${ }^{1,2}$, Dana Yahav-Shafir ${ }^{4}$, Haim Berkenstadt ${ }^{4}$, Ori Vatury ${ }^{1,2}$, \\ Ilan Hay $^{1,2}$, Micha S. Feinberg ${ }^{1,2}$, Victor Guetta ${ }^{1,2}$, Paul Fefer ${ }^{2,3}$ \\ ${ }^{1}$ Leviev Cardiovascular Institute, Sheba Medical Center, Israel \\ ${ }^{2}$ Sackler School of Medicine, Tel Aviv University, Israel \\ ${ }^{3}$ Department of Internal Medicine H, Sheba Medical Center, Israel \\ ${ }^{4}$ Department of Anesthesiology, Sheba Medical Center, Israel
}

\begin{abstract}
Background: The treatment of choice for severe rheumatic mitral stenosis (MS) is balloon mitral valvuloplasty (BMV). Assessment of MS severity is usually performed by echocardiography. Before performing BMV, invasive hemodynamic assessment is also performed. The effect of anesthesia on the invasive assessment of MS severity has not been studied. The purpose of the present study was to assess changes in invasive hemodynamic measurement of MS severity before and after induction of general anesthesia. Methods: The medical files of 22 patients who underwent BMV between 2014 and 2020 were reviewed. Medical history, laboratory, echocardiographic and invasive measurements were collected. Anesthesia induction was performed with etomidate or propofol. Pre-procedural echocardiographic measurements of valve area using pressure half time, and continuity correlated well with invasive measurements using the Gorlin formula.

Results: After induction of anesthesia the mean mitral valve gradient dropped by $2.4 \mathrm{mmHg}$ $(p=0.153)$ and calculated mitral valve area (MVA) increased by $0.2 \mathrm{~cm}^{2}(p=0.011)$. A wide variability in individual response was observed. While a drop in gradient was noted in 14 patients, it increased in 7. Gorlin derived MVA rose in most patients but dropped in 4. Assuming a calculated MVA of $1.5 \mathrm{~cm}^{2}$ and below to define clinically significant MS, 4 patients with pre-induction MVA of $1.5 \mathrm{~cm}^{2}$ or below had calculated MVA above $1.5 \mathrm{~cm}^{2}$ after induction.

Conclusions: The impact of general anesthesia on the hemodynamic assessment of MS is heterogeneous and may lead to misclassification of MS severity. (Cardiol J 2022; 29, 2: 245-251)
\end{abstract}

Key words: mitral stenosis, anesthesia, hemodynamics, mitral balloon valvuloplasty

\section{Introduction}

Rheumatic heart disease (RHD), once the most common cause of valvular heart disease, is now relatively rare in the Western world. Mitral stenosis (MS), the most common manifestation of
RHD, is still encountered in areas with migrant populations. The treatment of choice for rheumatic MS is balloon mitral valvuloplasty (BMV) [1]. The indications for valve intervention depend on the presence of compatible symptoms and objective evidence of significant MS. The American Heart

Address for correspondence: Rafael Kuperstein, MD, Leviev Heart Center, Sheba Medical Center, Tel Hashomer 5265601, Israel, tel: (+972) 3-2433, fax: (+972) 3-5305789, e-mail: rafael.kuperstein@sheba.health.gov.il

Received: 8.06.2021

Accepted: 10.10 .2021

Early publication date: 25.10 .2021

*Contributed equally

This article is available in open access under Creative Common Attribution-Non-Commercial-No Derivatives 4.0 International (CC BY-NC-ND 4.0) license, allowing to download articles and share them with others as long as they credit the authors and the publisher, but without permission to change them in any way or use them commercially. 
Association (AHA) and the American College of Cardiology (ACC) guidelines define severe MS as a mitral valve area (MVA) of $1.5 \mathrm{~cm}^{2}$ or less. In these cases, BMV is recommended if there are no procedural contra-indications and when there are favorable anatomical and clinical characteristics [2]. Diagnosis of significant MS depends primarily on echocardiographic assessment using trans-thoracic evaluation of valve gradients and area and recently three-dimensional transesophageal planimetry of the valve opening [3, 4]. Invasive hemodynamic assessment of mitral valve stenosis severity is performed routinely before BMV, however, hemodynamic changes in cardiac output and vascular resistance associated with anesthesia, often performed before BMV, may affect hemodynamic measurements of valvular stenosis severity. The purpose of the current study was to assess changes in invasive hemodynamic measurement of MS severity before and after induction of general anesthesia.

\section{Methods}

\section{Patient population and data collection}

The clinical records of 22 patients who underwent anesthesia during BMV procedure at the Sheba Medical Center Invasive Cardiology Unit between July 2014 to March 2020 were investigated. The research protocol was approved by our Institutional Review Board (5453-18-SMC).

Baseline characteristics including age, gender, relevant medical history, New York Heart Association (NYHA) functional class before and after the procedure, laboratory tests, echocardiographic measurements before and after the procedure and invasive measurements were collected in a retrospective manner from the electronic patient record and documented in an electronic case report form. A letter of consent was sent to patients who had missing data and were later called in order to collect the information.

\section{Echocardiographic examination}

Transthoracic echocardiography (TTE) was performed within 1 month prior to the BMV. Transvalvular gradients were assessed using Doppler flow velocity analysis after optimization of gain settings and beam orientation. Maximal and mean gradients were obtained. Valve area was evaluated by planimetry, pressure half time (PHT) and by the continuity equation according to the current American Society of Echocardiography (ASE) guidelines [5]. Transesophageal echocardiography (TEE) was performed routinely before anesthesia. The diagnosis of significant MS was confirmed, and the presence of intra-cardiac thrombus was ruled out. All procedures were guided by continuous TEE imaging.

\section{Hemodynamic assessment, BMV technique, and anesthesia}

All patients underwent invasive hemodynamic assessment prior to induction of anesthesia. Pressures were recorded in the right atrium, right ventricle, pulmonary artery and pulmonary capillary wedge (PCW) using a 7F Swan-Ganz flotation catheter. Simultaneous pressures in the PCW and left ventricle (LV) were recorded to assess the transmitral gradient. Cardiac output was calculated using measured Fick $\left(\mathrm{O}_{2}\right.$ consumption was measured with a Cosmed Fitmate PRO, Rome, Italy). Valve area was assessed using the Gorlin equation [6]. After a decision was made to proceed with BMV, patients underwent anesthesia induction and endotracheal intubation. Invasive hemodynamic assessment was repeated under anesthesia. If no contra-indication was noted, trans-septal puncture was performed under TEE guidance (catheter used) and BMV was performed using Inoue Balloon technique [7]. Post-valvuloplasty measurements were repeated after BMV.

Anesthesia was induced using fentanyl in a dose of $1-2 \mu \mathrm{g} / \mathrm{kg}$ body weight and hypnotic drug (etomidate $0.2-0.4 \mathrm{mg} / \mathrm{kg}$ or propofol $1-2 \mathrm{mg} / \mathrm{kg}$ ) and rocuronium bromide in a dose of $0.5 \mathrm{mg} / \mathrm{kg}$ was used to facilitate muscle relaxation before orotracheal intubation. Patients were ventilated in volume-controlled mode with tidal volume of 6- $8 \mathrm{~mL} / \mathrm{kg}$ and respiratory rate adjusted to achieve $\mathrm{EtCO}_{2}$ values of $30-35 \mathrm{mmHg}$. Anesthesia was maintained using inhaled anesthetics (isoflurane or sevoflurane) and phenylephrine was used to treat hypotension following the induction of anesthesia.

\section{Statistical analysis}

Variables were described according to their properties. Categorical variables are reported in frequencies and percentages. These variables are included only as baseline descriptive data for the study population, and no statistical testing was required in this case. The distribution for all continuous variables was assessed using a visual histogram and the Shapiro-Wilk test for normality, and none of them were found to have a normal distribution. When testing for significant differences, these variables are shown as median (intraquartile range), with differences tested using the Wilcoxon signed-rank test. All statistical tests were 2 -sided, and a p value of less than 0.05 was considered significant. 
The statistical analysis was carried out with the use of $\mathrm{R}$ version 3.6.1 software (The R Foundation) and R-studio 1.2.5001 (R Studio, Inc.).

\section{Results}

The study included 22 patients who underwent hemodynamic assessment of mitral valve stenosis before and after induction of anesthesia. The clinical and echocardiographic characteristics are shown in Table 1 . Mean age was $55 \pm 12$ and $91 \%$ were women. They had no major comorbidities and most suffered from NYHA class II-III heart failure. The pre-procedural echocardiographic assessment of mitral valve gradients and area correlated well with invasive measurements before anesthesia. The different echocardiographic measurements including PHT, planimetry and continuity were compared to the calculated invasive valve area using the Gorlin formula. All 3 methods derived valve areas similar to the calculated Gorlin MVA ( $p=0.7, p=0.08, p=0.4$, respectively).

Hemodynamic assessment before and after induction of anesthesia are shown in Table 2. After induction of anesthesia a non-significant rise in cardiac output and cardiac index and drop in mean and peak aortic pressures, as well as a drop in pulmonary arterial pressure were observed. A numerical reduction in pulmonary vascular resistance and in systemic vascular resistance were observed. Mean mitral valve gradient dropped by $2.4 \mathrm{mmHg}(\mathrm{p}=0.15)$ (Fig. 1) and calculated MVA increased by $0.2 \mathrm{~cm}^{2}$ $(\mathrm{p}=0.01)$ (Fig. 2). Patient level data showing post-
Table 1. Baseline clinical and pre-procedural echocardiographic characteristics.

\begin{tabular}{|c|c|}
\hline Age [years] & $55.2 \pm 11.6$ \\
\hline Female & $90.9 \%$ \\
\hline Hypertension & $13.6 \%$ \\
\hline Diabetes mellitus & $9.1 \%$ \\
\hline Dyslipidemia & $36.4 \%$ \\
\hline $\mathrm{GFR}<60 \mathrm{~mL} / \mathrm{min}$ & $5 \%$ \\
\hline Creatinine & $0.7 \pm 0.2$ \\
\hline Hemoglobin [mg/dL] & $12.4 \pm 1.4$ \\
\hline NYHA I & $5.9 \%$ \\
\hline NYHA II & $47.1 \%$ \\
\hline NYHA III & $47.1 \%$ \\
\hline NYHA IV & $0 \%$ \\
\hline LVEF [\%] & $60.4 \pm 3.2$ \\
\hline LA area $\left[\mathrm{cm}^{2}\right]$ & $30 \pm 6.8$ \\
\hline LA diameter $[\mathrm{cm}]$ & $4.8 \pm 1.1$ \\
\hline LV mass $[\mathrm{g}]$ & $128.3 \pm 20$ \\
\hline Mean mitral gradient [mmHg] & $9.8 \pm 4.6$ \\
\hline Peak mitral gradient [mmHg] & $18.9 \pm 8.87$ \\
\hline MVA by planimetry $\left[\mathrm{cm}^{2}\right]$ & $1 \pm 0.2$ \\
\hline MVA by pressure half time $\left[\mathrm{cm}^{2}\right]$ & $1.1 \pm 0.3$ \\
\hline MVA by continuity $\left[\mathrm{cm}^{2}\right]$ & $0.9 \pm 0.3$ \\
\hline Wilkins score & $6.5 \pm 1.5$ \\
\hline AV disease $>$ mild & $7.1 \%$ \\
\hline TV disease $>$ mild & $28.6 \%$ \\
\hline $\begin{array}{l}\text { Systolic pulmonary artery } \\
\text { pressure }[\mathrm{mmHg}]\end{array}$ & $50.6 \pm 17.3$ \\
\hline
\end{tabular}

Table 2. Hemodynamic measurements before and after induction of anesthesia.

\begin{tabular}{lccc}
\hline & Before induction & After induction & P \\
\hline Cardiac output & $4.0(3.1-5.7)$ & $5.2(4.0-6.1)$ & 0.26 \\
Cardiac index & $2.0(1.7-3.2)$ & $2.9(2.4-3.9)$ & 0.11 \\
Aorta mean pressure & $86(82-97)$ & $60(56-66)$ & 0.12 \\
Aorta systolic pressure & $112(104-126)$ & $85(76-88)$ & 0.12 \\
Left ventricular systolic pressure & $126.0(113-132)$ & $95(83-106)$ & 0.03 \\
Mean pulmonary artery pressure & $30(26-34)$ & $26(22-33)$ & 0.17 \\
Mean wedge pressure & $22(19-27)$ & $19(16-25)$ & 0.11 \\
Mean mitral valve gradient & $13.0(10.0-20.2)$ & $10.5(7.2-15.5)$ & 0.15 \\
Mitral valve area & $1.0(0.9-1.3)$ & $1.4(1.0-1.5)$ & 0.01 \\
Pulmonary vascular resistance & $1.7(1.0-2.8)$ & $1.2(1.0-1.7)$ & 0.06 \\
Systemic vascular resistance & $20.5(14.2-30.5)$ & $12.5(9.0-17.0)$ & 0.15 \\
\hline
\end{tabular}




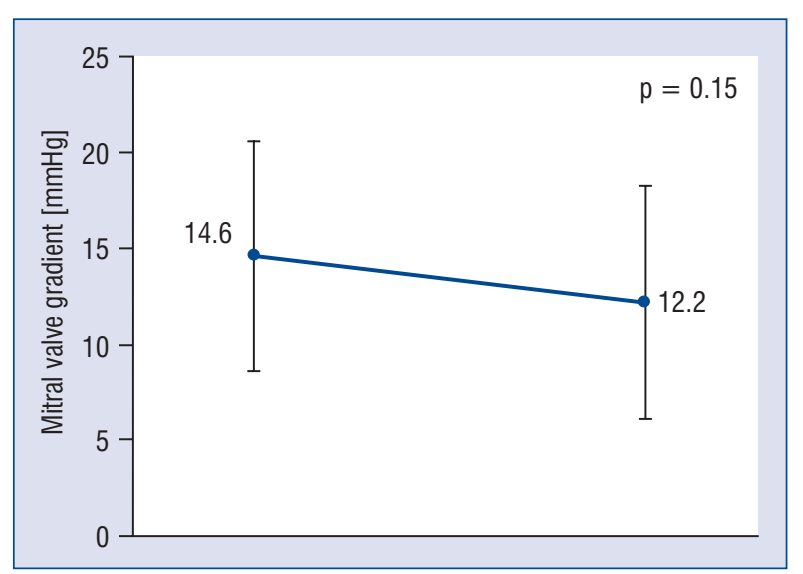

Figure 1. Total change in mitral valve gradient before and after anesthesia induction.

induction changes in mitral valve mean gradient are shown in Figure 3 and post-induction changes in calculated valve area in Figure 4. As shown, there is wide variability in individual patient response to anesthesia induction. While a drop in gradient was observed in 14 patients, in 7 patients the gradient actually increased. Of all patients who showed a drop in gradient, the heart rate increased in 6 and decreased in 4 . No change in heart rate was noted in the other cases. Also, there was wide variability in the magnitude of drop in pressure and in 4 patients a drop greater than $10 \mathrm{mmHg}$ was observed. Assuming a cutoff of $10 \mathrm{mmHg}$ defining severe MS, 6 out of 17 patients with a pre-induction gradient greater or equal to $10 \mathrm{mmHg}$ dropped below this threshold after induction. Conversely, 2 out of 5 patients with a pre-induction gradient below $10 \mathrm{mmHg}$ rose above this threshold after. Similar findings are shown in calculated MVA, using the Gorlin equation, after induction. While most patients demonstrated an increase in valve area, 4 patients actually showed a reduction in area. Again, there was a large variability in the magnitude of change with 5 patients demonstrating greater than $0.5 \mathrm{~cm}^{2}$ increase in calculated valve. Assuming a calculated MVA of $1.5 \mathrm{~cm}^{2}$ and below to define clinically significant MS, 4 patients with pre-induction MVA of $1.5 \mathrm{~cm}^{2}$ or below had calculated MVA above $1.5 \mathrm{~cm}^{2}$ after induction. However, no patients with pre-induction MVA above $1.5 \mathrm{~cm}^{2}$ changed category after induction.

\section{Discussion}

Herein, hemodynamic severity of MS in patients undergoing BMV under anesthesia was assessed. Significant variability was found when valve evaluation

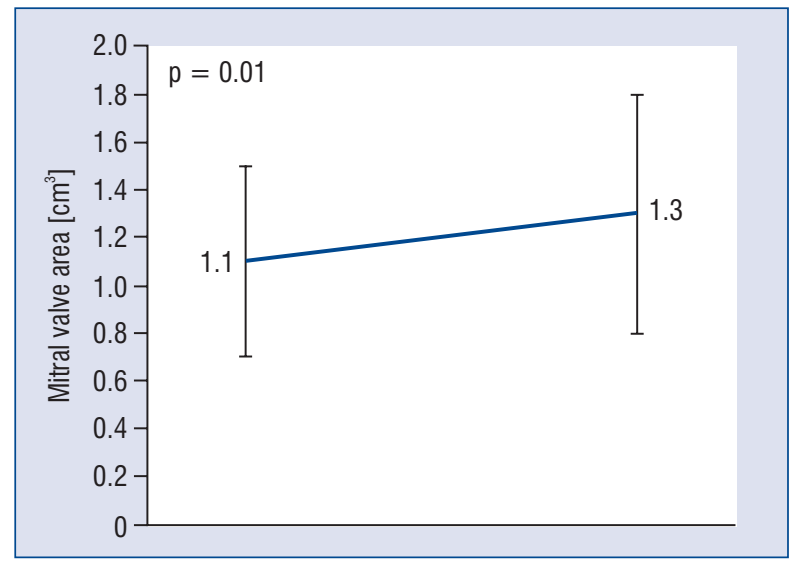

Figure 2. Total change in mitral valve area before and after anesthesia induction.

was performed immediately before and immediately after induction of anesthesia. Furthermore, variability occurred in both directions and has the potential to either under-estimate or over-estimate MS severity after induction. According to available research, no previous studies have reported on this issue.

In the present study, pre-induction hemodynamic assessment of trans-mitral gradient and valve area using the Gorlin equation showed good correlation with pre-procedural TTE performed within 1 month prior to BMV. Previous studies have also demonstrated good correlation between hemodynamic assessment using the Gorlin equation and echocardiographic assessment using PHT or the continuity equation [8-10].

Even 70 years after its formulation, the Gorlin formula is still widely considered the standard of reference in the assessment of valvular stenosis [6]. The formula was derived from two simplified equations describing steady state flow through an orifice. It was validated in 11 patients with MS and compared with valve areas estimated at valve surgery or at autopsy. The Gorlin formula demands three determinations to be made: determination of a constant; determination of trans-valvular gradient; and determination of cardiac output (transvalvular flow) [11]. Errors in determination of trans-mitral gradient and cardiac output can lead to inaccuracies in MVA assessment. However, it has also been shown that the constant used in the Gorlin formula is not constant across all hemodynamic conditions. Cannon et al. [12], using a wide range of flows and pressures across valves of known orifice area in a hemodynamically accurate pulsatile flow model, was able to show that calculated valve area increased with increasing flow even 


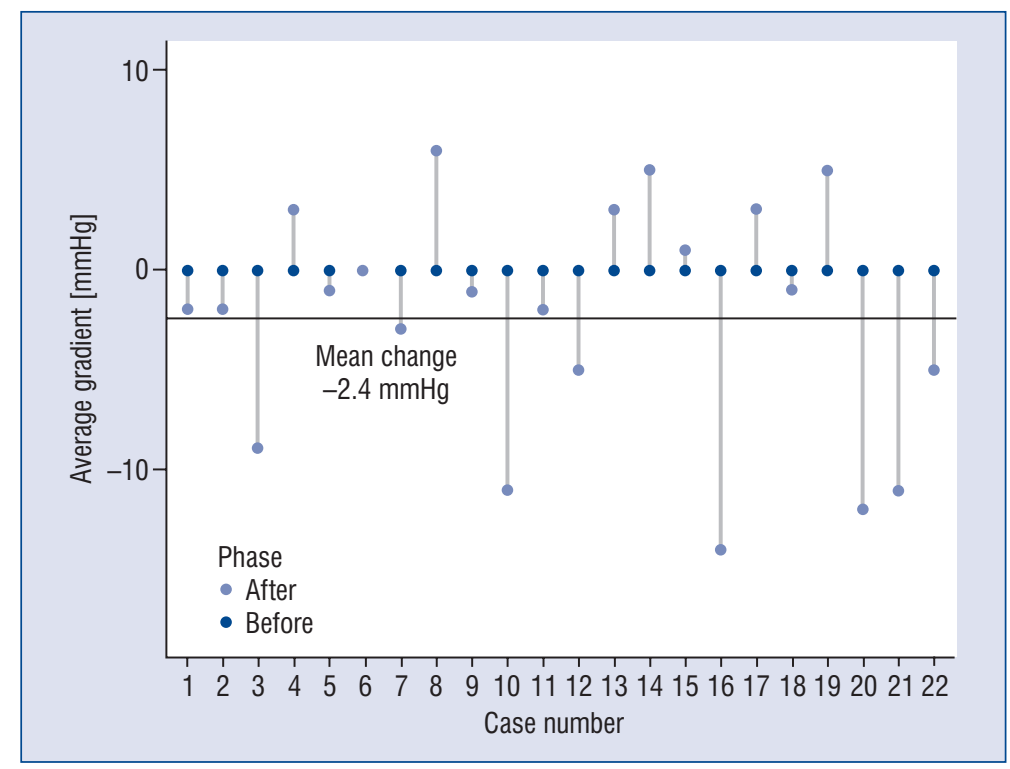

Figure 3. Mean change in mitral valve gradient before and after anesthesia induction.

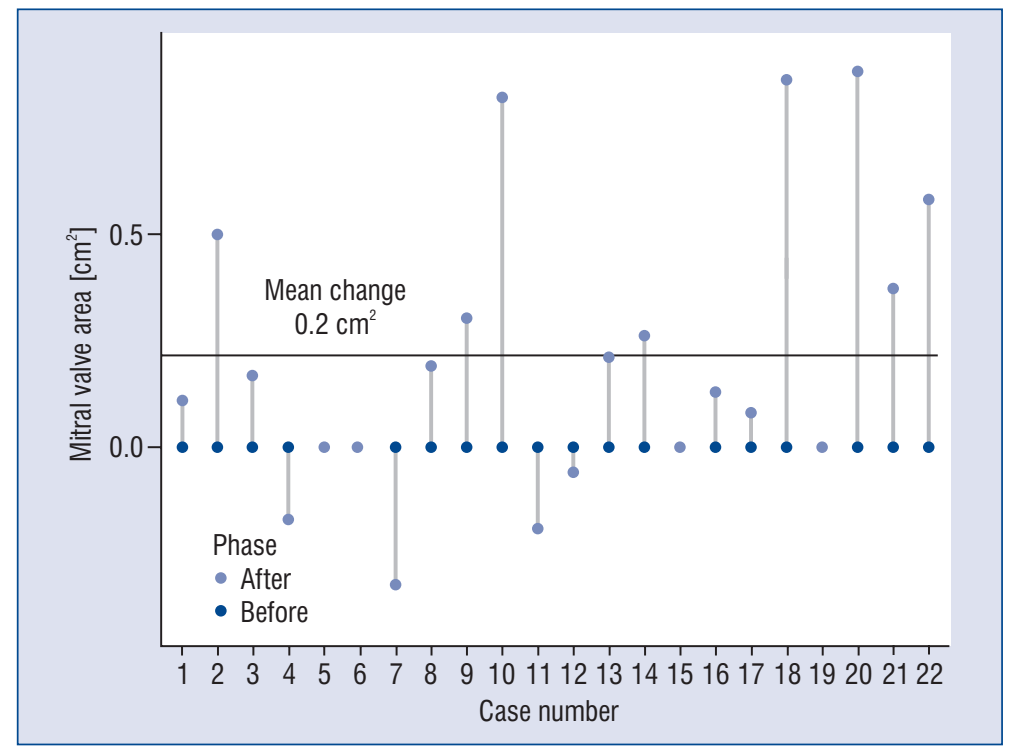

Figure 4. Mean change in mitral valve area before and after anesthesia induction.

though the actual orifice area was constant. Segal et al. [13] and others $[14,15]$ confirmed these findings and found that the Gorlin formula may actually under-estimate the true orifice area, particularly in patients with low cardiac output. Interestingly, and in contrast to echocardiographic MVA assessment using PHT and continuity equation which have been shown to increase significantly with increasing heart rate [16, 17], the Gorlin formula has been shown to be relatively stable across a wide range of heart rates induced by ventricular pacing [17].
According to available research, no previous studies have assessed the effects of general anesthesia on the hemodynamic assessment of MS severity. While as a group the mean changes in trans-valvular gradient and area (Figs. 3, 4) are small, however, due to inter-individual variability in response to anesthesia, striking changes were observed in individual patients. In fact, changes in gradient class were observed in 8 of 22 patients (severe to non-severe in 6 of 17 and non-severe to severe in 2 of 5). More importantly, 4 patients 
with pre-induction MVA of $1.5 \mathrm{~cm}^{2}$ or below (severe MS) had calculated MVA above $1.5 \mathrm{~cm}^{2}$ after induction. Induction of anesthesia and positive pressure ventilation are associated with changes in cardiac output, pulse rate, blood pressure and pulmonary and systemic resistance which can influence trans-mitral gradient and flow [18, 19]. Since the constant used in the Gorlin formula has been shown to be inconstant under different flow and pressure conditions, the interplay of these factors is likely responsible for the variability observed in the hemodynamic assessment of MS before and after induction of anesthesia.

In summary, hemodynamic evaluation of MS severity before BMV under general anesthesia is unreliable. As stated in the current ACC guidelines [2], echocardiography is a reliable diagnostic modality to diagnose, follow, and decide on the timing for therapy in patients with MS. Additional hemodynamic assessment may be performed in cases with questionable symptoms for whom there is discordance between the clinical and echocardiographic findings. In these difficult cases, invasive hemodynamic assessment can add important information as the valve gradient is measured directly rather than calculated from Doppler flow velocity. In these cases, the assessment of MS should be performed preferably without any sedation to avoid influencing the hemodynamic measurements.

\section{Limitations of the study}

This study has several limitations. It is single-center with a limited number of patients. The anesthetic protocol, while similar, was not uniform and thus it is impossible to eke out the particular influence of specific anesthetic drugs.

In addition, while in some major centers BMV is performed under conscious sedation with TTE monitoring, peri-procedural monitoring with TEE under general anesthesia as described in this study is widely utilized in many centers before this procedure.

\section{Conclusions}

Pre-induction hemodynamic assessment of MS using the Gorlin formula correlates well with echocardiographic measurements of MVA and trans-valvular gradients. Large variability in trans-mitral gradient and smaller yet significant over-estimation of valve area was observed after induction of anesthesia.

Conflict of interest: None declared

\section{References}

1. Harb SC, Griffin BP. Mitral valve disease: a comprehensive review. Curr Cardiol Rep. 2017; 19(8): 73, doi: 10.1007/s11886017-0883-5, indexed in Pubmed: 28688022.

2. Otto C, Nishimura R, Bonow R, et al. 2020 ACC/AHA Guideline for the Management of Patients With Valvular Heart Disease: A Report of the American College of Cardiology/American Heart Association Joint Committee on Clinical Practice Guidelines. J Am Coll Cardiol . 2021; 77(4): e25-e197, doi: 10.1016/j. jacc.2020.11.018, indexed in Pubmed: 33342586.

3. Wunderlich NC, Dalvi B, Ho SY, et al. Rheumatic mitral valve stenosis: diagnosis and treatment options. Curr Cardiol Rep. 2019; 21(3): 14, doi: 10.1007/s11886-019-1099-7, indexed in Pubmed: 30815750.

4. Wunderlich NC, Beigel R, Siegel RJ. Management of mitral stenosis using 2D and 3D echo-Doppler imaging. JACC Cardiovasc Imaging. 2013; 6(11): 1191-1205, doi: 10.1016/j. jcmg.2013.07.008, indexed in Pubmed: 24229772.

5. Zamorano JL, Badano LP, Bruce C, et al. EAE/ASE recommendations for the use of echocardiography in new transcatheter interventions for valvular heart disease. J Am Soc Echocardiogr. 2011; 24(9): 937-965, doi: 10.1016/j.echo.2011.07.003, indexed in Pubmed: 21867869.

6. Gorlin R, Gorlin SG. Hydraulic formula for calculation of the area of the stenotic mitral valve, other cardiac valves, and central circulatory shunts. I. Am Heart J. 1951; 41(1): 1-29, doi: 10.1016/0002-8703(51)90002-6, indexed in Pubmed: 14799435.

7. Inoue K, Owaki T, Nakamura $\mathrm{T}$, et al. Clinical application of transvenous mitral commissurotomy by a new balloon catheter. J Thorac Cardiovasc Surg. 1984; 87(3): 394-402, indexed in Pubmed: $\underline{6} 700245$.

8. Hatle L, Angelsen B, Tromsdal A. Noninvasive assessment of atrioventricular pressure half-time by Doppler ultrasound. Circulation. 1979; 60(5): 1096-1104, doi: 10.1161/01.cir.60.5.1096, indexed in Pubmed: 487543.

9. Nakatani S, Masuyama T, Kodama K, et al. Value and limitations of Doppler echocardiography in the quantification of stenotic mitral valve area: comparison of the pressure half-time and the continuity equation methods. Circulation. 1988; 77(1): 78-85, doi: 10.1161/01.cir.77.1.78, indexed in Pubmed: 3335074.

10. Dev V, Singh LS, Radhakrishnan S, et al. Doppler echocardiographic assessment of transmitral gradients and mitral valve area before and after mitral valve balloon dilatation. Clin Cardiol. 1989; 12(11): 629-633, doi: 10.1002/clc.4960121104, indexed in Pubmed: 2582654.

11. Reynolds JD, Cook KD, Reynolds JD, et al. Improving fast atom bombardment mass spectra: The influence of some controllable parameters on spectral quality. J Am Soc Mass Spectrom. 1990; 1(2): 149-157, doi: 10.1016/1044-0305(90)85051-M, indexed in Pubmed: 24248743.

12. Cannon SR, Richards KL, Crawford M. Hydraulic estimation of stenotic orifice area: a correction of the Gorlin formula. Circulation. 1985; 71(6): 1170-1178, doi: 10.1161/01.cir.71.6.1170, indexed in Pubmed: 3995711.

13. Segal J, Lerner D, Miller DC, et al. When should doppler-determined valve area be better than the Gorlin formula?: Variation in hydraulic constants in low flow states. J Am Coll Cardiol. 1987; 9(6): 1294-1305, doi: 10.1016/s0735-1097(87)80469-2.

14. Reynolds T. The determination of aortic valve area by the Gorlin formula: what the cardiac sonographer should know. J Am 
Soc Echocardiogr. 1990; 3(4): 331-335, doi: 10.1016/s08947317(14)80318-0, indexed in Pubmed: 2206552.

15. Ubago JL, Figueroa A, Colman T, et al. Hemodynamic factors that affect calculated orifice areas in the mitral hancock xenograft valve. Circulation. 1980; 61(2): 388-394, doi: 10.1161/01. cir.61.2.388, indexed in Pubmed: 7351065.

16. Rijsterborgh H, Mayala A, Forster T, et al. The reproducibility of continuous wave Doppler measurements in the assessment of mitral stenosis or mitral prosthetic function: the relative contributions of heart rate, respiration, observer variability and their clinical relevance. Eur Heart J. 1990; 11(7): 592-600, doi: 10.1093/ oxfordjournals.eurheartj.a059764, indexed in Pubmed: 2373094.
17. Harcombe AA, Ludman PF, Wisbey C, et al. Balloon mitral valvuloplasty: comparison of haemodynamic and echocardiographic assessment of mitral stenosis at different heart rates in the catheterisation laboratory. Int J Cardiol. 1999; 68(3): 253-259, doi: 10.1016/s0167-5273(98)00374-x, indexed in Pubmed: 10213275.

18. Soni N, Williams P. Positive pressure ventilation: what is the real cost? Br J Anaesth. 2008; 101(4): 446-457, doi: 10.1093/bja/ aen240, indexed in Pubmed: 18782885.

19. Michard F. Changes in arterial pressure during mechanical ventilation. Anesthesiology. 2005; 103(2): 419-28; quiz 449, doi: 10.1097/00000542-200508000-00026, indexed in Pubmed: 16052125. 